\title{
Sa'el jun ontonal, la búsqueda del bienestar, la autonomía y la paz desde Las Abejas de Acteal
}

\author{
Carla Beatriz Zamora Lomelí \\ El Colegio de la Frontera Sur, San Cristóbal de las Casas, Chiapas, México. \\ Email: czamora@ecosur.mx
}

Resumen: El presente trabajo aborda el origen de la organización Sociedad Civil Las Abejas en el estado de Chiapas, México y su configuración en áreas de trabajo que atienden a lo económico, lo social y lo cultural para ilustrar los procesos que han desarrollado como alternativas a la violencia y el conflicto social y político que se han mantenido desde la década de los noventa en la región y que en 1997 tuvo su episodio más trágico con la matanza de cuarenta y cinco personas integrantes de la organización que aquí se observa. Ante tal situación, Las Abejas emergen como un actor colectivo que opta por la noviolencia y se suma a la reivindicación de los derechos de los pueblos indígenas desde la construcción de sus procesos de autonomía orientados hacia lo que definen como el LekilKujlejal, el buen vivir, articulándose en distintos proyectos de trabajo colectivo como alternativas de vida.

Palabras clave: violencia, autonomía, buen vivir, Las Abejas, Chiapas

\section{Sa'eljunontonal, the pursuit of well-being, autonomy and peace from Las Abejas of Acteal}

\begin{abstract}
This paper addresses the origin of the organization Las Abejas Civil Society in the state of Chiapas, Mexico and its configuration in work areas serving economic, social and cultural areas, in order to illustrate the processes that has been developed as alternatives to violence and social and political conflict, which has been maintained since the nineties in the region and in 1997 had its most tragic episode with the killing of forty- five members of the organization that is here presented. In front of that situation, Las Abejas emerge as a collective actor who chooses non-violence and relates to the vindication of the rights of indigenous peoples trough building their autonomous processes oriented towards what they define as the LekilKujlejal, good living, articulating in different projects of collective work and life alternatives.
\end{abstract}

Keywords: violence, autonomy, good living, Las Abejas, Chiapas

\section{Sa'eljunhoontonal, buscando o bem-estar, a autonomia e a pazdesdeLasAbejas de Acteal}

Resumo: Este artigo trata da origem da organização Sociedade Civil Las Abejas no estado de Chiapas, México e sua configuração em áreas de trabalho que atendem o económico, social e cultural para ilustrar os processos que foram desenvolvidos como alternativas à violência e os conflitos sociais e políticos que se 
tem mantido desde a década de noventa na região e que em 1997 teve o seu episódio mais trágico com a morte de quarenta e cinco membros da organização abordada aqui. Nesta situação, Las Abejas emerge como um ator coletivo que escolhe a nãoviolência e que contribui para a reivindicação dos direitos dos povos indígenas para construir seus processos de autonomia orientados para o que eles definem como o LekilKujlejal,o BomViver, articulandose em diferentes projetos de trabalho coletivo como alternativas de vida.

Palavras-chave:violência, autonomia, Bom Viver, Las Abejas, Chiapas

$* * *$

\section{Introducción}

El estado de Chiapas, ubicado en el sureste de México, es una entidad cuya diversidad biológica, social y cultural se enmarca en procesos históricos donde han prevalecido relaciones de poder y subordinación que se expresan en diversos niveles del tejido social. Concretamente para el caso que se aborda en este trabajo, la configuración y procesos de la organización Sociedad Civil Las Abejas, en la región de Los Altos de Chiapas, se encuentran distintas tensiones sociales y políticas que han desencadenado momentos de violencia en la región, como los hechos ocurridos el 22 de diciembre de 1997 cuando fueron asesinados cuarenta y cinco hombres, mujeres y niños pertenecientes a la organización por grupos paramilitares. A pesar de tales hechos, Las Abejas se han mantenido como un grupo pacifista que trabaja en varias áreas para alcanzar el bienestar colectivo, el sa'el jun ontonal, que en lengua indígena tsotsil significa «la búsqueda del bienestar».

De esta manera, la Sociedad Civil Las Abejas emerge en la década de los noventa como un actor que representa "un trabajo organizativo, lento pero muy profundo porque se arraiga en las costumbres y tradiciones de las comunidades indígenas, es decir, en el respeto a la decisión comunitaria, en el mandar obedeciendo, en la recuperación de la cultura indígena. Por su naturaleza, poco a poco han ido definiendo su caminar, han optado por no vincularse a los partidos políticos, sobretodo porque sus intereses no están incluidos en las plataformas político-electorales, porque el objetivo de su lucha no es la toma del poder sino la búsqueda de solución a sus demandas (Hidalgo, 1998: 53), y que desde su inicio se ha mantenido como un grupo independiente al Ejército Zapatista de Liberación Nacional, aunque comparten el mismo territorio y reivindicaciones por los derechos y cultura indígenas optando por el camino de la autonomía indígena de facto al margen de la operación de un Estado que históricamente les ha excluido.

Los procesos que aquí se exponen tienen lugar en la región de Los Altos de Chiapas, concretamente en las veintiocho comunidades del municipio de Chenalhóque integran la organización, cuyo número de integrantes ronda las dos mil personas indígenas tsotsiles que habitan en colindancia con los municipios de Pantelhó y Chalchihuitán. 
El quehacer de Las Abejas se basa en alternativas desde la noviolencia y el trabajo organizado atendiendo el área económica (con la cooperativa cafetalera Maya Vinic); el área de salud (con promotores comunitarios y el rescate de la medicina alternativa); la dimensión cultural (con proyectos de comunicación, teatro y música); la revalorización del trabajo artesanal de las mujeres, entre otras estrategias encaminadas hacia el lekilkuxlejal, de cuyos modos de aproximación en la vida cotidiana se dará cuenta en este trabajo.

\section{Una historia construyendo el panal: la organización Sociedad Civil Las Abejas}

Nos mataron pequeños e indefensos, pero renacimos gigantes e inmortales. Como Junajpú e Ixbalanqué descendimos al inframundo para derrotar

a los señores de la oscuridad. Ahora somos fragmentos de la luz que impide que todo sea noche. Somos voces que emergen del silencio y de la muerte, somos esperanza y ejemplo.

Jiménez, 2008:0

Durante finales del siglo XIX y hasta mediados del XX en Chiapas ocurrieron procesos de concentración de la tierra en pocas manos, lo que dio paso a la acumulación a través de grandes extensiones hacendarias y finqueras cuyos propietarios ejercían un poder violento hacia los trabajadores, en su mayoría, indígenas de la región. Después de la Revolución Mexicana de 1910, comenzó un reparto agrario en todo el país, pero en el caso de Chiapas tal reparto fue tan lento que incluso existen procesos agrarios sin terminar.

El rezago agrario ha generado tensiones sociales en torno a la tenencia de la tierra y ha detonado procesos de lucha a través de numerosas organizaciones y movimientos sociales de corte indígena y campesino de distintas filiaciones políticas. La región en donde ocurre el proceso organizativo del que aquí se da cuenta, se encuentra en la zona de Los Altos de Chiapas, una serranía donde el promedio de tenencia de la tierra por productor es de media hectárea cuyas calidades son variables según la altitud y geografía en donde se ubiquen, lo que propicia actividades como la producción cafetalera y el trabajo de la milpa que combina el cultivo del maíz, frijol y calabaza, entre otros.

En los pueblos indígenas, la tierra es un bien que se hereda a los hijos de la familia campesina; anteriormente se les daba sólo a los hombres de la familia y ahora es un bien repartido entre hombres y mujeres del núcleo familiar; sin embargo, debido al crecimiento demográfico, la tierra se convierte en un recurso escaso para repartir entre todos los miembros de una familia, y esto genera conflictos por la tenencia que se originan en el plano familiar y se extienden al territorio indígena que envuelve al grupo (Zamora, 
2003:86), como ocurrió en el caso que detonó la primera acción colectiva de la organización que aquí se aborda. Expresado en sus propias palabras narran:

“En el año de 1992, tres hermanos: Agustín, Catarina y María Hernández López, heredan, de su padre recientemente fallecido, un terreno de 120 hectáreas en la comunidad de Tsajalch'en, municipio de Ch'enavo', Los Altos de Chiapas. En un contexto en el cual la costumbre social no permitía la tenencia de tierra por parte de mujeres, Agustín buscó exigir la exclusividad de la propiedad e ignorar el derecho de sus hermanas a recibir la herencia” (Las Abejas, 2016b:0).

El hecho derivó en una escalada de violencia y conflicto político que provocó dos grupos: el que apoyaba al hermano y el que apoyaba a las mujeres de la familia en la lucha por su derecho a la tierra. Este conflicto fue creciendo e involucrando organizaciones como la Organización Popular para la Defensa de las Culturas, miembros de Solidaridad CampesinoMagisterial (SOCAMA). Quienes apoyaban a las hermanas Hernández recorrieron varias comunidades "para formar una organización que les diera la posibilidad de defenderse de los ataques del grupo encabezado por Agustín; bajo el cobijo de la Sociedad de Productores de Café de Tzajalchen, citaron a una reunión el 9 de diciembre de 1992 en esa comunidad. Acudieron unas 22 comunidades de Chenalhó y ahí formaron Las Abejas” (Hidalgo, 1998: 56). Posteriormente el conflicto aumentó el nivel de violencia con la agresión armada por parte de las personas que respaldaban a Agustín, teniendo como resultado el asesinato de una persona y la agresión a tres familias que incluyeron la violación sexual de una mujer embarazada esposa de uno de los heridos. En el ejercicio del poder y la impunidad, en lugar de arrestar a los presuntos agresores se emitieron órdenes de aprehensión en contra de integrantes de la naciente organización de Las Abejas, que para entonces movilizó a cerca de mil quinientas personas en una manifestación que duró cinco días hasta lograr la liberación de las personas falsamente acusadas.

Las Abejas nace entonces como una respuesta organizada y pacífica ante el conflicto y la violencia, teniendo como base el trabajo de la Diócesis de San Cristóbal de las Casas y la Pastoral Indígena, que desde la década de los 70 formó catequistas indígenas en las comunidades con un perfil analítico que les permitió vislumbrar sus problemas cotidianos y buscar alternativas de solución propiciando de alguna manera el proceso organizativo en las comunidades (Zamora, 2003: 72 ), por ello se encuentra presente una importante dimensión religiosa desde el catolicismo como parte de la identidad organizativa, lo cual se expresa en sus propios términos al explicar su origen: "había que juntarnos porque somos una multitud y construir nuestra casa como el panal de las abejas, donde todos trabajemos en colectivo y que gocemos de lo mismo, producir miel para todos. Así somos como las abejas en una sola caja, no nos dividimos y caminamos junto con nuestra reina, que es el reino de Dios” (Centro de Derechos Humanos Fray Bartolomé de las Casas, 1998a: 57) y se acentúa que "desde la fundación de nuestra 
organización optamos por la lucha No Violenta inspirados por la lucha y ejemplo de Jesús. Gracias a nuestros fundadores y fundadoras que hicieron ese esfuerzo y trabajo duro y por su reflexión junto con Jtotik Samuel Ruiz ${ }^{1}$, que nadie debe ser preso y presa injustamente” (Las Abejas, 2015b: 5).

Con tal convicción y cohesión organizativa, Las Abejas resiste a las dinámica gubernamental del asistencialismo y el clientelismo, por lo que se mantiene fuera de los procesos electorales y de partidos políticos desarrollando sus propios proyectos colectivos sin recibir recursos del gobierno, en una suerte de resiliencia que sobrevive a episodios graves de violencia y momentos de escisión entre algunos miembros de la organización, como se da cuenta en los siguientes apartados.

\section{Las heridas de Acteal y la violencia paramilitar}

A partir del levantamiento armado del Ejército Zapatista de Liberación Nacional, los procesos que ha tomado el conflicto han ido variando en veintidós años de la insurgencia armada. Inicialmente larespuesta gubernamental fue la confrontación armada, posteriormente se acordó la vía del diálogo y la negociación que llevaría a la firma de los Acuerdos de San Andrés sobre Derechos y Cultura Indígena en 1996. Sin embargo, poco tiempo después de esa firma, el gobierno federal desconoció tales acuerdos y fueron redactadas legislaciones que escasamente reconocían el derecho a la libre autodeterminación de los pueblos indígenas.

En ese contexto, posterior al desconocimiento del gobierno a los acuerdos en 1996, se desencadenaron procesos de violencia en diversas partes de la entidad, muchos de ellos auspiciados como parte de una estrategia de contrainsurgencia desde el Estado que propició la formación de grupos paramilitares en el norte y Los Altos de Chiapas; concretamente "en Chenalhó, un grupo de campesinos militantes del Partido Revolucionario Institucional fue organizado y entrenado por elementos del Ejército Nacional Mexicano y protegido por elementos de la Policía de Seguridad Pública” (CDHFBC, 1998b: 34).

En 1997 los conflictos y el nivel de violencia en el municipio de Chenalhó fueron constantes. Las agresiones de los grupos paramilitares (como asesinatos selectivos, quema de casas, amenazas y despojo de tierras) ocasionaron el desplazamiento de la población de sus comunidades de origen, entre ellos se contaban más de dos mil quinientas personas integrantes de Las Abejas que se refugiaron en cuatro campamentos ( $O p$. Cit. Hidalgo, 1998: 55).

El 22 de diciembre de ese año, “aproximadamente a las 10:30 horas se encontraba parte de la comunidad de Acteal junto con los desplazados de otras comunidades en la ermita católica orando para pedir por la paz en Chenalhó. La gran mayoría de los orantes llevaban tres días de ayuno. Los refugiados y habitantes de Acteal escucharon una gran cantidad de bala- 
zos provenientes de varias direcciones acercándose a la ermita. Según algunos testigos, un grupo numeroso de al menos 90 personas dispararon con armas de alto calibre y con balas expansivas contra los hombres, mujeres y niños desarmados. Los campesinos intentaron huir y esconderse en diversos lugares [...] Los disparos duraron hasta aproximadamente las 6:00 de la tarde. Fueron asesinados 45 campesinos: 15 niños, 21 hombres y 9 mujeres. Además quedaron 25 heridos” (Op. Cit. CDHFBC, 1998a: 10).

Esta fuerte agresión aunado a la evidente omisión gubernamental para solucionar los conflictos desde su origen y desmantelar los grupos paramilitares cobijados desde el partido político en el poder, generó reacciones de solidaridad a nivel nacional e internacional que desde entonces han mantenido una presencia constante en Acteal. A pesar de las dificultades de sobrevivir a tal nivel de violencia, Las Abejas mantuvieron su convicción pacifista, reforzando poco a poco su compromiso para lograr la paz con justicia y dignidad, con base en la noviolencia que implica un método de intervención desde "la acción, el deber y el convencimiento por la justicia dentro del respeto total de las personas y la vida de los adversarios, renunciando al uso de todo tipo de violencia para conseguir esos objetivos” (López, 2001 en López, 2004:0).

Así, en 2001 comenzaron los retornos de algunas familias miembros de Las Abejas a sus comunidades de origen, a pesar de que las condiciones para su regreso eran endebles incluso después de haber firmado un Pacto de Respeto Mutuo $^{2}$ impulsado por el gobierno estatal de aquella época a través de la Comisión de Reconciliación para las Comunidades en Conflicto. El acercamiento con las instancias de gobierno, fue un detonante de algunas fracturas organizativas, por ejemplo "el retorno de los desplazados agudizó conflictos al interior de la propia organización, entre la organización y [Organizaciones No Gubernamentales] que antes la apoyaban, con el equipo pastoral, y con los zapatistas [lo cual llevó] a un desdibujamiento de Las Abejas, lo que quiere decir que la política de reconciliación oficial reposicionó actores, dividió y confrontó a quienes antes fueron aliados” (Bellinghausen, 2002: 24).

Aunado a lo anterior, en el 2002 un miembro de la organización fue postulado como candidato a la presidencia municipal de Chenalhó, lo que generó la primera división de la organización entre quienes se acercaron al gobierno estatal para solicitar apoyos y quienes se mantuvieron al margen en la construcción de la autonomía que tenían visiones contrapuestas sobre el desarrollo de la organización, dado que los primeros decidieron utilizar su capital político para solicitar programas y subsidios gubernamentales estableciendo alianzas con partidos políticos, mientras que el grupo que continúa como Sociedad Civil Las Abejas ha mantenido una postura política contraria a las acciones de gobierno. Esta división se hizo más clara entre 2008 y 2009 cuando quienes optaron por recibir apoyos para proyectos sociales por parte del gobierno se autoproclamaron como "Las Abejas, A.C.” y se autoproclamaron como interlocutores entre la organización y el gobierno. La ruptura definitiva se produjo cuando en una de las negocia- 
ciones se proponía "firmar un documento en donde se afirmaba que Las Abejas se retractaban entorno a afirmaciones en las que se decía que seguían existiendo grupos paramilitares en la zona” (Las Abejas, 2011:1), lo cual generó inconformidad y ruptura.

Finalmente, en 2015 se presentó otra ruptura, esta vez entre los familiares y sobrevivientes de las víctimas de la masacre, quienes se articularon como el Consejo Pacifista Sembradores de Paz, disputando la estructura directiva de Las Abejas desde un nuevo órgano de gobierno, lo cual fue desconocido por la Mesa Directiva, máximo órgano de decisión de la Sociedad Civil Las Abejas.

Actualmente la estructura organizativa se encuentra articulada de la siguiente forma:

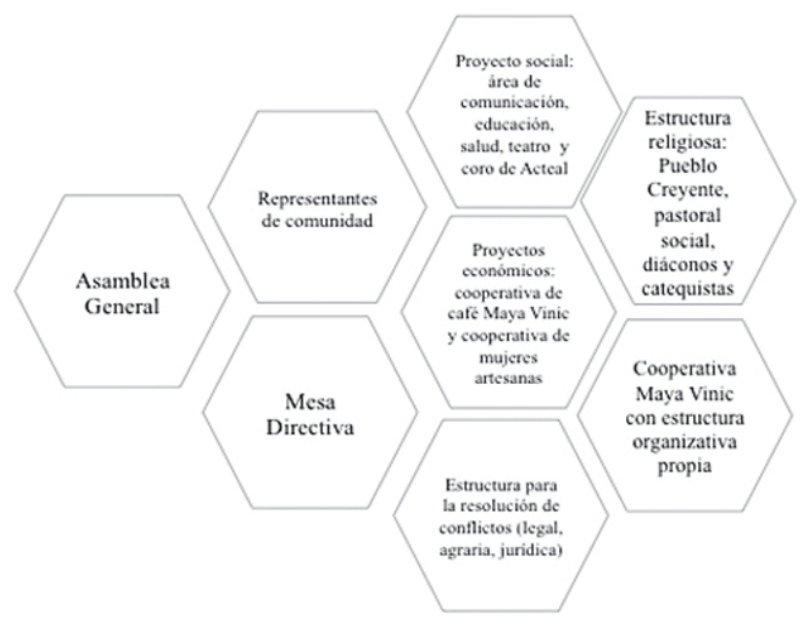

Fuente: Elaboración propia

Muchas cosas han pasado en los 18 años que han seguido a la trágica matanza del 97, como la disolución de los campamentos de desplazados y el retorno a sus comunidades, con excepción del campamento de Acteal Centro, que se mantiene como el centro de concentración en donde se encuentra la oficina de la organización y fueron enterradas las personas víctimas de la masacre. Acteal recuerda que la herida se mantiene abierta a consecuencia de una serie de actos de impunidad que entre otras cosas, han puesto en libertad a los perpetradores de la masacre sin aprehender a los autores intelectuales de la barbarie, muchos de ellos funcionarios de varios niveles de gobierno. Ante tales actos, la organización ha respondido desde la solidaridad y la paz manteniendo viva la memoria y la dignidad, tal 
como expresan: "reconocemos que las divisiones duelen mucho, porque es una de las armas del mal gobierno para acabar una comunidad, un pueblo, un movimiento. Pero, reconocer la debilidad no significa retroceder o rajarse, sino es para fortalecer la lucha y el proceso de la construcción del LekilKuxlejal, (buen vivir), Jun o’ontonal (que el corazón no esté partido), Ich'eltamuk' (respetar a la otra y al otro)” (Las Abejas, 2015b: 3); en otros términos "necesitamos unir más la fuerza y buscar que haya un camino más correcto, que haya una vida más equitativa, LekilKuxlejal es dejar una herencia para nuestros hijos buscando la paz que está en la base de la palabra de Dios” (entrevista a Sebastián Pérez, presidente de la Mesa Directiva de Las Abejas, 22 de enero de 2016).

En este sentido, la noción del lekilkuxlejal implica dimensiones culturales, políticas, ambientales, sociales y económicas cercanas a la idea de Buen Vivir concebido como "una alternativa orientada a tratar de rehacer la vida socioambiental a partir de la solidaridad humana y con la naturaleza, no solo en la actividad económica y productiva, sino en todas las dimensiones de la existencia social: el trabajo, el sexo, la autoridad, colectiva, la subjetividad y la naturaleza” (Marañón, 2014: 41), lo cual constituyen principios vinculados a la cosmovisión indígena que desde un marco jurídico implica el derecho a la libre autodeterminación de los pueblos indígenas, con lo cual la concepción del lekilkuxlejal se asemeja a otros proyectos de construcción de alternativas como el zapatista, y a su vez se incorpora las luchas y resistencias de otros pueblos indígenas en una apuesta colectiva anclada en el desarrollo de sus propios modos de vida orientados hacia el bienestar colectivo.

\section{"La memoria es un acto de justicia". Lekilchapanel, la justicia verdadera}

En el 2009, la Suprema Corte de Justicia de la Nación resolvió la libertad de veinte paramilitares acusados de cometer la masacre en 1997, bajo el argumento de violaciones a las garantías procesales de éstos. Treinta más fueron liberados después con la misma resolución. La complejidad del proceso jurídico que resolvió la Corte generó dudas entre la sociedad, lo que conduce a afirmar que se trató de fuertes actos de impunidad, toda vez que no se encontró nadie sentenciado por el crímen.

El nivel de desconfianza de la sociedad en las instituciones gubernamentales en México es latente, por lo que hechos como el descrito abonan en tal ambiente de desconfianza. Ante ello, Las Abejas optan por hacer de la memoria un acto de justicia, es decir, mes a mes cada día 22 se realiza una ceremonia religiosa en recuerdo de las personas asesinadas en la masacre y se lee un pronunciamiento derivado del análisis político de la organización que generalmente expresa su solidaridad con otras causas sociales. De esta manera, la organización apunta "si queremos una justicia de verdad, nosotras y nosotros los pueblos organizados de México debemos de construir 
una Justicia Verdadera, Digna, cabal y humanizada. Y a lo largo de los 18 años como Organización de la Sociedad Civil Las Abejas y sobrevivientes de la masacre de Acteal, hemos decidido caminar y construir el Lekil Chapanel (La Justicia Verdadera), porque ese es uno de los caminos para garantizar que no se repitan más crímenes contra la humanidad y así vivir en paz y en armonía en nuestra nación mexicana (...) el camino para encontrar una [tal justicia], está en nuestras manos, eso quiere decir que nosotros y nosotras hombres y mujeres de pueblos conscientes tenemos que trabajar y llevarla a la práctica desde nuestras comunidades y pueblos” (Las Abejas, 2015: 3).

Así, una forma de hacer justicia es mantener viva la memoria colectiva, expresada en foros como el Tribunal Permanente de los Pueblos capítulo México, un espacio integrado por personas con prestigio social y ético que desde una instancia no gubernamental examina las causas de violaciones a derechos humanos y emite una sentencia que da a conocer para la opinión pública denunciando a los autores de tales violaciones.

Las agresiones contra integrantes de Las Abejas han seguido ocurriendo, como en el 2013 cuando un grupo de la Colonia Puebla despojó a los integrantes de la organización de un terreno destinado para la construcción de una iglesia católica, las familias de Las Abejas salieron desplazadas ante las amenazas cada vez más violentas de los grupos agresores. En 2015, las agresiones contra miembros de la Sociedad Civil Las Abejas cobraron la vida de uno de ellos, quien fue asesinado para despojarle de su tierra. Lo anterior son solamente un par de ejemplos que muestra que la justicia sigue siendo omisa para resolver los conflictos en la región, de ahí la pertinencia de Las Abejas para hacer un llamado a La Otra Justicia trabajando de manera conjunta en redes de solidaridad para denunciar a quienes están detrás de las acciones violentas.

\section{El camino de la autonomía para construir la paz desde el LekilKuxlejal}

A partir de la reinvidicación por el ejercicio de los derechos de los pueblos indígenas, el proceso de la autonomía en organizaciones como la que aquí se ha abordado ha implicado una definición política que en principio se mantiene al margen de las acciones de gobierno, elige a sus autoridades con base en sus usos y costumbres y cuida su territorio desde la armonía con el medio ambiente, como afirman: "Nuestra lucha es por un mundo más humano, nuestra lucha es por la paz, la Justicia Verdadera, por la vida y por la Madre Tierra (...) seguiremos construyendo nuestras propias leyes. Afirmamos que los acuerdos de San Andrés Sakamch'en de los Pobres, son parte de nuestros instrumentos para la Justicia Verdadera. Queremos contar con mujeres y hombres que sepan arreglar nuestros problemas, que sean dignos y no corruptos, sabias y sabios, que guien con buen corazón, con conciencia limpia y comprometida con la Verdad” (Las Abejas, 2015c:0). 
En otros términos, se trata de un proceso que "produce una modificación de la interacción de los sujetos que de él forman parte, así como de su solidaridad (...) los que participan en el proceso colectivo tienen la conciencia de constituir una colectividad que tiene en su exterior algo con lo que está relacionada, o algo con lo que combate: un sistema exterior" (Alberoni, 1984: 38), en este caso, las acciones de gobierno y aquellas derivadas de los proyectos que atentan contra la naturaleza como la minería o las hidroeléctricas a cuyas luchas Las Abejas acuden expresando su solidaridad con otros actores.

De esta manera, aunado al trabajo político hay una identidad colectiva que refleja la complejidad interna del actor y las relaciones del actor con el ambiente (Melucci, 2002: 66). Esta identidad colectiva se enmarca en procesos culturales y simbólicos anclados en la cosmovisión indígena tsotsil que a su vez conlleva una carga de valores éticos de respeto a la vida y a la diversidad, lo que hace que buena parte de los integrantes de la organización se constituyan como sujeto- actores, considerando que "el Sujeto indica con claridad la prioridad atribuida al individuo, no abstraído de sus pertenencias, sus situaciones y las influencias que sufre, sino definido como actor, capaz de modificar su medio. El actor-Sujeto debe tener la última palabra contra todas las formas de garante metasocial del orden social” (Touraine, 1997:86).

Es importante mencionar que en términos de su constitución como actores, existe congruencia con la definición pacifista la Sociedad Civil Las Abejas, que claramente no pertenece a la estructura de la organización político militar del EZLN, aunque comparten el trabajo por la reivindicación de los derechos de los pueblos indígenas y la construcción de la autonomía, esto fue claro cuando en 1994 declararon: "así como nuestro cuepo tiene dos piernas, la sociedad tiene que tener dos piernas, el EZLN es una y nosotros como civiles somos la otra. No somos el EZLN porque no respondemos a sus órdenes, tenemos que hacer la lucha pacífica y no con armas. Somos hermanos con ellos y para los dos nuestro principal enemigo es el gobierno y las autoridades priístas que organizan los paramilitares" (Op. Cit. Hidalgo: 62); además, ambas organizaciones confluyen en el Congreso Nacional Indígena, una red de cerca de 35 pueblos organizados desde 1996 para defender el derecho a la libre autodeterminación de los pueblos indígenas. En tal reivindicación se fundan los trabajos colectivos emprendidos por Las Abejas, que a continuación serán abordados.

\section{Antsetiktsa'ikLekilKuxlejal . Mujeres construyendo buena vida}

En el contexto de la urgencia postconflicto, la solidaridad nacional e internacional fue constante en Acteal. Este fue un elemento que contribuyó al fortalecimiento de la organización en varias áreas, una de ellas fue el grupo de mujeres de la organzación, quienes desde 1998 comenzaron a 
articularse para la comercialización de los textiles artesanales que tradicionalmente han realizado.

Así, el trabajo textil se ha ido diversificando a fin de ofrecer distintos productos a un mercado fuera de la comunidad. Hasta 2003, dicho proyecto comprendía cerda de 240 mujeres provenientes de 16 comunidades de Chenalhó.

Los bordados que hacen a las prendas son representaciones de su cosmovisión indígena, así bordan al vinik (hombre) la antsetik (mujer), animales, guías de maíz, y flores de la región, entre otras creaciones. Generalmente trabajan con manta blanca e hilos de colores creando prendas para uso cotidiano. Los productos del trabajo de las mujeres artesanas, se comercializan en una pequeña tienda instalada en la comunidad de Acteal y también en un espacio de venta en San Cristóbal de las Casas y el grupo es coordinado por una representante general y se organizan con el trabajo voluntario de las mujeres que destinan tiempo para vender los productos en la tienda (Op. Cit. Zamora, 2003: 110), aunque también ocurre que de manera independiente cada persona ofrece sus productos de manera directa a quienes llegan a visitar la comunidad de Acteal.

Para el 2006 el grupo de mujeres se posiciona en la estructura organizativa a través del consejo de mujeres que busca impulsar "la participación permanente en las decisiones de la organización y representación informada en eventos nacionales e internacionales” (Las Abejas, 2013:0).

Otro importante proyecto encabezado por las mujeres comenzó en el 2012 con la creación de cajas de ahorro y préstamo a través del "Banco de las mujeres”3 , que otorga préstamos colectivos para financiar trabajos productivos y con ello apoyar al fortalecimiento de la autonomía desde la independencia económica (Ibid).

\section{Pensamiento y corazón para una comunicación comunitaria}

De igual manera, el acompañamiento y presencia de diversos actores de la red de solidaridad que se ha mantenido con posterioridad al conflicto, permitió que en 2003 se adquiriera equipo para la transmisión de frecuencia modulada a nivel regional, con lo que nació la radio ChanulPom, un esfuerzo encabezado en buena medida por jóvenes hombres y mujeres “con el objetivo de mantener informadas a [a las] comunidades y dar a conocer [la] realidad, así como fomentar [la] cultura, fortalecer [la] lucha por la paz, la justicia y la construcción de [la] autonomía como pueblos originarios de México” (Las Abejas, 2016a: 0).

La importancia de la comunicación fue valorada desde la posibilidad de “construir una política verdadera, con participación de la gente. [Ofreciendo] información para que nuestro pueblo conozca los problemas que tiene, comprenda de dónde vienen y tenga herramientas para participar 
activamente en su resolución. De esta forma se logra la construcción de una verdadera democracia, una planteada desde el pueblo organizado que lucha por construirse un buen vivir” (Las Abejas, 2016a).

Sin embargo, este esfuerzo colectivo se truncó temporalmente cuando ocurrió la escisión de Las Abejas en 2009, dado que el grupo disidente se llevó el equipo con el cual se estaba realizando el proyecto. Afortunadamente con el apoyo de organizaciones no gubernamentales y el trabajo propio de la Sociedad Civil Las Abejas, para el 2010 fue posible retomar el trabajo de comunicación con más equipo y nueva capacitación. “El área de comunicación de la Sociedad Civil Las Abejas funciona como una de las áreas de trabajo de la organización. Su tarea se plantea en torno a dos ejes: la comunicación interna o comunitaria y la externa o comunicación social de la organización. Para esto se vale de la producción de audio, video y comunicación gráfica” (Las Abejas 2016a: 0).

\section{Música para la consolación y teatro para la denuncia}

El coro de Acteal es un proyecto cultural dentro de las Abejas que a través de sus cantos promueve el ejercicio de los derechos humanos y la denuncia. Ha grabado 3 discos y ha realizado giras en el interior de la república y a nivel internacional en Italia y Francia, con la venta de los discos y con donativos se financian nuevas producciones y también se apoya el trabajo de autonomía de otras áreas previa discusión en el órgano directivo de la organización.

El origen del coro se encuentra anclado en el proceso religioso, como explica un integrante, "el coro nació porque antes de la matanza, se estaba haciendo un trabajo entre católicos y presbiterianos que era traducir la Biblia al tzotzil, nuestro propio idioma, ya que la gente indígena no entendía español; cuando ya estuvo terminada, los comités de la Biblia comenzaron a hacer una fiesta para conmemorarlo y se ensayó un canto, entre católicos y presbiterianos. Cuando sucedió la masacre, decidimos no quedarnos callados, ya que vivíamos en un gran sufrimiento, hasta en los campamentos, así empezamos a cantar nuestra realidad. De ser un coro religioso, pasó a ser un coro de consolación y denuncia, aunque su sentido de estar en contacto con Dios no se perdió, ya que cantan en las iglesias de las comunidades durante las fiestas patronales o comunales como bautizos, entierros, bodas, etcétera” (Zamora, 2003: 111).

Por otra parte, los grupos de jóvenes han trabajado desde hace algunos años en la puesta en escena de obras de teatro con contenidos de denuncia de violaciones a derechos humanos. Una de estas obras ha recreado lo ocurrido el 22 de diciembre de 1997 y se presenta en los aniversarios de la masacre como una forma de mantener viva la memoria colectiva. La expresión artística y visual de tales hechos impacta sensibilizando al espectador en la magnitud del daño producido por la violencia y las alterna- 
tivas que ha emprendido la organización para hacer frente a tal situación por la vía de la autonomía y de la paz.

\section{Salud y educación}

La atención a la salud fue una de las prioridades a cuidar de manera inmediata a la matanza de 1997, dadas las difíciles condiciones de vida a que estuvo expuesta la población desplazada y los efectos a la salud física y mental derivados de vivir un proceso tan violento. Así las primeras acciones fueron coordinadas por la Cruz Roja Mexicana, que estableció un centro de atención en Acteal y fue apoyado por organizaciones internacionales como Médicos Sin Fronteras.

Paulatinamente el servicio de atención a la salud ofrecido por personas ajenas a la comunidad se fue retirando, en el caso de la Cruz Roja se tomó una decisión de corte político que cuestionó la imparcialidad del organismo en el contexto del conflicto; empero, al mismo tiempo que unos se retiraban, otros siguieron llegando y desde el trabajo colectivo se retomó la importancia de la medicina tradicional y la herbolaria, con lo cual se desarrolló un proyecto para tener un centro de abasto de medicina herbolaria en el campamento de Acteal.

Al mismo tiempo, Las Abejas acordaron la organización de la Comisión de Salud que trabaja a través depromotores comunitarios capacitados en temas sanitarios que atienden padecimientos menores. En la actualidad se cuenta con una pequeña clínica instalada también en Acteal, donde se ofrece servicio de consultas y hospitalización intermedia.

Por otra parte, durante un periodo se intentó desarrollar un proyecto de educación autónoma para impartir educación básica a los niños y niñas de las comunidades integrantes de Las Abejas con contenidos curriculares propios, sin embargo este trabajo no logró realizarse y se acordó que el servicio sería proporcionado por la Secretaría de Educación del Estado, toda vez que tuviera la supervisión y consentimiento de la organización.

\section{La cooperativa de café Maya Vinic}

De igual manera que la mayoría de los proyectos para la construcción de la autonomía y el buen vivir, la cooperativa de pequeños productores cafetaleros Maya Vinic nace en el contexto de la reflexión derivada de los hechos de 1997. La zona de Los Altos ha sido una región cafetalera al menos desde la década de los setenta; sin embargo, a diferencia de otras regiones como el Soconusco (donde prevalecen las fincas cafetaleras con grandes extensiones), en los Altos la propiedad de la tierra por persona en promedio es menor a tres hectáreas, lo que aunado a las relaciones de poder en la zona (con predominio de caciques locales) en condiciones de produc- 
ción individual el café se compra por intermediarios que ofrecen el precio más bajo del mercado.

Ante esta situación, hubo algunos intentos para que los productores de Las Abejas se articularan con las cooperativas cafetaleras existentes en la región, tal fue el caso de la Sociedad de Productores de Café de Tzajalchen y de la Unión de Productores Majomut. Empero, derivado del acompañamiento de personas y redes de solidaridad con posterioridad al 97, se valoró la importancia de tener un espacio propio para la producción, transformación y comercialización del café de Las Abejas.

Así en julio de 1999 fue creada la Unión de Productores Maya Vinic, Sociedad Cooperativa de capital variable de responsabilidad limitada, cuyo objetivos iniciales fueron el fortalecimiento de la autonomía comunitaria, el aumento en la calidad de vida de las familias de los socios productores y el mejoramiento de las condiciones de producción y comercialización de los productos agrícolas, comenzando por el café, para posteriormente intentarlo con otros productos.

De esta manera, como en su momento expresaron los integrantes de la cooperativa, "la organización no sólo representa beneficio económico sino también dignidad y trato justo a nosotros. Es bueno que la cooperativa se organice. Juntos se obtiene un mejor precio. Sabemos que hay muchos intermediarios, que siempre llegan a nuestras casas a comprar café, pero robando mucho. Al organizarnos, conseguimos un precio más justo, para que la cosecha y la vida de las personas mejore y podamos vivir del fruto de nuestro trabajo. Es por esta razón que nos constituimos en una Sociedad Cooperativa, queremos que las ganancias sean comunitarias, justas y sobre todo que sean un soporte digno para nuestras familias" (Zamora, 2003: 155).

El inicio de la cooperativa fue en condiciones de operación muy rústicas: una pequeña casa construida con tablas y piso de tierra servía como centro de acopio, molido y envasado de las bolsas de café. Poco a poco se asomó el acompañamiento de grupos y personas solidarias con Maya Vinic que comenzaron con brigadas para acompañar a los productores al corte del café, en especial en comunidades donde existía la amenaza de los grupos paramilitares, como una forma de observar que no existieran más situaciones de violencia en su contra. Posteriormente gracias al producto de las ventas del café (en su mayoría destinadas al mercado internacional que de alguna manera se estableció con el contacto de los visitantes solidarios), se logró la compra de un terreno para construir una bodega de café, adquirir vehículos para la transportación y con apoyo de asesores externos obtuvieron la capacitación necesaria para certificar su café como un producto orgánico de alta calidad, incorporándose así a los nichos de mercado del comercio justo.

El interés de una cooperativa exitosa ha seguido atrayendo la atención de personas de diversas partes del mundo que buscan exportar el café 
de Maya Vinic a sus países. Una de las alianzas más sólidas de la cooperativa fue con personas provenientes de Japón, que desde hace al menos doce años han mantenido la relación comercial y de intercambio de saberes propiciando entre otras cosas, la venta directa del café en taza por parte de los productores en un establecimiento acondicionado para ello ubicado en la ciudad de San Cristóbal de las Casas, además de la tecnologización del proceso de transformación del café (tostado y molido) con maquinaria especializada en las instalaciones de las oficinas de la cooperativa, también con domicilio en la ciudad de San Cristóbal, adquiridas con apoyo de la cooperación internacional de aquél país. Todos esos procesos se han dado sin que la calidad del café haya disminuido, incluso por encima de las plagas y enfermedades que han afectado a los cafetales como la roya.

La integración del número de socios de Maya Vinic ha sido fluctuante desde su origen. Al principio había 800 socios, para el 2003 se contaban 592, cifra que cayó aún más cuando ocurrió la ruptura de la Sociedad Civil Las Abejas que ha sido referida con anterioridad. Actualmente en 2016 se tiene registro de 680 socios, de los cuales 300 cuentan con la certificación de café orgánico y el resto se encuentra en transición. Además, desde el 2002 comenzó otro proyecto dentro de Maya Vinic: la producción y comercialización de miel orgánica de cafetal. Hasta la fecha dicho proyecto ha ido creciendo y se cuenta con aproximadamente 129 socios que tienen alrededor de 1800 colmenas.

El esfuerzo por crecer y mantenerse como una cooperativa sólida considera como eje el bienestar entre las familias de los socios que la integranbuscando la diversificación productiva con otros cultivos como la nuez macadamia, además de la miel, y manteniendo la apertura del mercado que han obtenido a lo largo de los dieciocho años que llevan trabajando bajo este esquema.

\section{Alianzas y redes de solidaridad}

A lo largo de este texto, se ha referido a la emergencia de la solidaridad en el contexto de la escalada de violencia ocurrida en 1997 que culminaron con la masacre de 45 personas. Organizaciones no gubernamentales, grupos colectivos de todo tipo e individuos sin filiación política u organizativa expresaron entonces su indignación desde sus territorios por lo ocurrido, e incluso organizaciones creadas de manera expresa para investigar las violaciones a derechos humanos, como fue la creación en 1998 de la Comisión Civil Internacional de Observación por los Derechos Humanos.

Poco tiempo después, la presencia física de los visitantes en Acteal se hizo evidente. Un gran mapa colgado en la oficina de la Mesa Directiva de Las Abejas tomó registro de las latitudes de donde provenían: desde África y Australia hasta Suecia y Argentina, además de todos los estados de la República mexicana. 
En más de un caso la expresión de solidaridad fue más allá de una palabra, es decir, de alguna manera impulsaron proyectos como los aquí descritos, bien sea desde la capacitación, el apoyo económico o simplemente el trabajo voluntario que sumaba manos a las tareas cotidianas, siempre en el marco del respeto a la estructura organizativa de la Sociedad Civil Las Abejas que implica procesos de consulta comunitaria y establecimiento de acuerdos.

En 1999 la expresión de la solidaridad se plasmó en una obra realizada por el escultor danés Jens Galschiot titulada “columna de la infamia” la cual representa una columna de ocho metros con cuerpos apilados que reflejan situaciones de dolor que se ubica a la entrada del campamento de Acteal. La escultura se ha convertido en símbolo de la organización que con el dibujo de ésta firma las comunicaciones oficiales.

Es necesario mencionar que las visitas de personas extranjeras al territorio de Acteal (y a espacios zapatistas) fueron sancionadas por parte del gobierno mexicano que recrudeció su política en torno a la participación de personas de otros países en procesos relacionados particularmente con los movimientos sociales de Chiapas ${ }^{4}$. Ello ocurrió en un periodo de marcado autoritarismo político donde se desarrolló una guerra de baja intensidad impulsada por del ejército mexicano en contra de las comunidades organizadas en Chiapas, que pretendía desgastar los procesos organizativos con el incremento de la violencia por la vía de grupos paramilitares y la militarización de los territorios zapatistas organizados (paz armada). En ese escenario, numerosos grupos de personas de otros países que acudían a Chiapas para documentar las violaciones a derechos humanos fueron expulsados de México; tan solo en 1998 fueron expulsadas 144 personas, de acuerdo con datos de la organización Global Exchange (Global Exchange, 1999).

Las redes de solidaridad entonces se articularon con más fuerza entre mexicanos y extranjeros, para mantener el acompañamiento a las comunidades que vivían bajo la situación de violencia descrita. A partir de entonces, la Sociedad Civil Las Abejas incorpora las alianzas con distintos actores como parte del proceso de construcción del lekilkuxlejal, asumiendo que esta vía requiere “pensamientos y corazones diversos” (Op. Cit. Las Abejas, 2015b), ello ha implicado la apertura de redes con organizaciones de derechos humanos a nivel nacional e internacional y la sincronía con otros proyectos de búsqueda del buen vivir con distintos grupos indígenas.

Al mismo tiempo, las muestras de solidaridad emanan también desde la organización hacia otros grupos y organizaciones sociales que han vivido severas violaciones a sus derechos humanos, como por ejemplo, los familiares de los 43 jóvenes normalistas de Ayotzinapa desaparecidos por fuerzas del Estado en septiembre del 2014. En conjunto, las redes de solidaridad por y desde Acteal son una de las mayores fortalezas de la organización. 


\section{Conclusiones}

La Sociedad Civil Las Abejas es una organización multiactiva diversificada por su propio proceso de desarrollo que ha sobrevivido a un contexto de violencia severa, que lejos de desarticularla, la ha fortalecido gracias a la cohesión organizativa que camina hacia un proyecto común en la búsqueda del bienestar por la vía de la autonomía y la noviolencia.

Estas formas de trabajo constituyen alternativas desde la resistencia pacífica que recurren a una amplia red de solidaridad a varios nivelescombinando recursos para la puesta en marcha de los proyectos colectivos que buscan un modo de vida ejerciendo el derecho a la libre autodeterminación de los pueblos indígenas que se expresa en sus propias formas de gobierno colectivo (la Asamblea General, los delegados por comunidad y la Mesa Directiva, todos cargos voluntarios sin remuneración), y en la concreción de esfuerzos económicos como el Banco de Mujeres y la cooperativa de café y miel Maya Vinic; en el ejercicio de la memoria como una vía no violenta para la justicia, y en el desarrollo de trabajos comunitarios que reivindican la cultura de los pueblos indígenas a través de la comunicación en radio y audiovisual, la expresión artística en teatro social y en la música que comunica mensajes de fraternidad por parte del Coro de Acteal.

Finalmente estamos ante un actor colectivo dinámico que se esfuerza por llevar a la práctica el ejercicio de la autonomía con expresiones que pretenden alcanzar el LekilKuxlejal o buen vivir, como una opción para el florecimiento de las comunidades que integran la organización. 
Polis, Revista Latinoamericana, Volumen 15, $N^{\circ}$ 43, 2016

\section{Notas}

${ }^{1}$ Obispo de la Diócesis de San Cristóbal de las Casas de 1959 al 2000, quien se caracterizó por su trabajo desde la teología de la liberación y la Opción Preferencial por los Pobres, a favor de la lucha por los derechos humanos y de los pueblos indígenas.

${ }^{2}$ El Pacto de Respeto Mutuo fue un documento negociado por el gobierno estatal y firmado entre los entonces representantes de Las Abejas y los dirigentes de otros grupos con filiación política partidista para garantizar la libertad de tránsito, la libertad de asociación y la libertad religiosa.

${ }^{3}$ El Banco de las Mujeres es una iniciativa que se basa en el esquema de ahorro y préstamo, donde desde el 2012 se comenzaron a operar préstamos para el desarrollo de proyectos colectivos.

${ }^{4}$ El marco legal para ello fue el artículo 33 Constitucional, donde se confiere al Ejecutivo la facultad de expulsar inmediatamente de su territorio, sin necesidad de juicio previo y sin conceder recurso de amparo, a todo extranjero que juzgue inconveniente o se inmiscuya en asuntos políticos del país. 


\section{Bibliografía}

Alberoni, Francesco (1984), Movimiento e institución. Teoría general. Editora Nacional, Madrid.

Arias, Reynaldo (2015), Discurso del presidente de Maya Vinic, Seminario de Economía Social, Solidaria y Popular de la Facultad de Ciencias Sociales de la Universidad Nacional Mayor de San Marcos, Lima, disponible al 29 de enero de 2016 en: http://economiassolidarias.unmsm.edu.pe/sites/default/ files/Reynaldo\%20Arias_Maya\%20Vinic\%20Mexico_0.pdf

Bellinghausen Hermann (2002), “Autonomía indígena, alternativa ante conflictos comunitarios en Chiapas, afirma investigador”, en: Diario La Jornada, Distrito Federal.

Centro de Derechos Humanos Fray Bartolomé de las Casas (1998a) Acteal: entre el duelo y la lucha. CDHFBC. San Cristóbal de las Casas.

Ídem (1998b), Camino a la masacre. Informe especial sobre Chenalhó. CDHFBC. San Cristóbal de las Casas, México.

Global Exchange (1999), Extranjeros de conciencia. Campaña del gobierno mexicano contra observadores de derechos humanos en Chiapas. Red Nacional de Organismos Civiles Todos los Derechos para Todos, Centro de Derechos Humanos Miguel Agustín Pro Juárez, Global Exchange y Comisión Mexicana de Promoción y Defensa de Derechos Humanos, Distrito Federal.

Hidalgo, Onésimo (1998), “El vuelo de Las Abejas”, en Centro de Derechos Humanos Fray Bartolomé de las Casas, Acteal, una herida abierta. ITESO, Tlaquepaque.

Jiménez, José Alfredo (2008), Acteal. 10 años de impunidad ¿y cuántos más? Documental, Komanilel, San Cristóbal de las Casas.

Las Abejas de Acteal(2011), La Sociedad Civil Las Abejas desmiente información publicada por Boca de Polen[on line], disponible al 1 de abril de 2016 en: http://acteal.blogspot.mx/2011/11/la-sociedad-civil-las-abejasdesmiente.html

Ídem (2013), Gira nacional de las mujeres abejas de Acteal[on line], disponible al 10 de diciembre de 2015 en: http://acteal.blogspot.com.es/2013/05/ gira-nacional-de-las-mujeres-abejas-de.html

Ídem (2015), La Memoria es un acto de Justicia, XVIII Conmemoración de la masacre de Acteal, comunicado del 22 de diciembre [on line], disponible al 23 de diciembre de 2015 en: http://acteal.blogspot.com.es/2015/12/lamemoria-es-un-acto-de-justicia-xviii_22.html 
Ídem (2015a) Cómo vamos caminando y trabajando en La Otra Justicia, comunicado del 22 de septiembre[on line], disponible al 23 de diciembre de 2015 en:http://acteal.blogspot.mx/2015/09/como-vamos-caminando-y-trabajando-en-la.html

Ídem (2015b) Hoy hacemos fiesta, aunque el mal gobierno no le guste, comunicado del 10 de diciembre [on line], disponible al 23 de diciembre de 2015 en: http://acteal.blogspot.mx/2015/12/hoy-hacemos-fiesta-aunque-elmal.html

Ídem (2015c) Pronunciamiento conjunto del Foro Caminando La Otra Justicia [on line], disponible al 29 de marzo de 2016 en http:// acteal.blogspot.mx/2015/10/pronunciamiento-conjunto-del-foro.html

Ídem (2016a), Área de comunicación de Las Abejas de Acteal [on line], disponible al 23 de diciembre de 2015 en: http://acteal.blogspot.mx/p/areade-comunicacion-de-las-abejas.html

Ídem (2016b), Historia de Las Abejas [on line], disponible al 5 de enero de 2016 en: http://acteal.blogspot.mx/p/historia-de-las-abejas.html

López Martínez, Mario “Noviolencia para generar cambios sociales” en: Polis, Revista de la Universidad Bolivariana, vol. 3, núm. 9, 2004, p. 0 Universidad de Los Lagos Santiago, Chile.

Marañón Pimentel, Boris (coord.) (2014), Buen vivir y descolonialidad. Crítica al desarrollo y la racionalidad instrumentales. Universidad Nacional Autónoma de México, Instituto de Investigaciones Económicas, Distrito Federal.

Melucci, Alberto (1999) “La acción colectiva como construcción social”. En:Estudios Sociológicos, vol. IX, núm. 26, Colegio de México. Distrito Federal.

Touraine, Alain (1997) ¿Podremos vivir juntos?, Fondo de Cultura Económica, Ciudad de México.

Zamora Lomelí, Carla Beatriz (2003), El proceso organizativo de la Sociedad Civil Las Abejas y la Cooperativa Cafetalera Maya Vinic, y su impacto en el espacio social regional en los Altos de Chiapas (1999-2003). Tesis de Maestría en Estudios Regionales, Instituto de Investigaciones Dr. J.M.L. Mora, Distrito Federal. 